\title{
Article
}

\section{Using FEM to Assess the Effect of Orthodontic Forces on Affected Periodontium}

\author{
Ionut Luchian ${ }^{1}$, Maria-Alexandra Martu 1,*(D), Monica Tatarciuc ${ }^{2, *}$, Mihaela Monica Scutariu ${ }^{3,+}$, \\ Nicoleta Ioanid ${ }^{4,+}$, Liliana Pasarin ${ }^{1}$, Diana Cristala Kappenberg-Nitescu ${ }^{1}$, Ioana-Andreea Sioustis ${ }^{1}$ \\ and Sorina Mihaela Solomon ${ }^{1}$
}

1 Department of Periodontology, Faculty of Dental Medicine, “Grigore T. Popa” University of Medicine and Pharmacy, 16 Universitatii Str., 700115 Iasi, Romania; ionut.luchian@umfiasi.ro (I.L.); liliana.pasarin@umfiasi.ro (L.P.); diana-cristala.nitescu@umfiasi.ro (D.C.K.-N.); ioana-andreea.sioustis@umfiasi.ro (I.-A.S.); sorina.solomon@umfiasi.ro (S.M.S.)

2 Department of Dental Technology, Faculty of Dental Medicine, "Grigore T. Popa" University of Medicine and Pharmacy, 16 Universitatii Str., 700115 Iasi, Romania

3 Department of Oro-Dental Diagnostics, Faculty of Dental Medicine, "Grigore T. Popa" University of Medicine and Pharmacy, 16 Universitatii Str., 700115 Iasi, Romania; mihaela.scutariu@umfiasi.ro

4 Department of Fixed Prosthodontics, Faculty of Dental Medicine, "Grigore T. Popa" University of Medicine and Pharmacy, 16 Universitatii Str., 700115 Iasi, Romania; nicoleta.ioanid@umfiasi.ro

* Correspondence: maria-alexandra.martu@umfiasi.ro (M.-A.M.); monica.tatarciuc@umfiasi.ro (M.T.)

+ Authors with equal contribution as the first author.

check for

updates

Citation: Luchian, I.; Martu, M.-A.; Tatarciuc, M.; Scutariu, M.M.; Ioanid, N.; Pasarin, L.; Kappenberg-Nitescu, D.C.; Sioustis, I.-A.; Solomon, S.M. Using FEM to Assess the Effect of Orthodontic Forces on Affected Periodontium. Appl. Sci. 2021, 11, 7183. https://doi.org/10.3390/ app11167183

Academic Editor: Vincenzo Quinzi

Received: 3 July 2021

Accepted: 2 August 2021

Published: 4 August 2021

Publisher's Note: MDPI stays neutral with regard to jurisdictional claims in published maps and institutional affiliations.

Copyright: (c) 2021 by the authors. Licensee MDPI, Basel, Switzerland. This article is an open access article distributed under the terms and conditions of the Creative Commons Attribution (CC BY) license (https:/ / creativecommons.org/licenses/by/ $4.0 /)$.
Abstract: Orthodontic treatment in patients with no periodontal tissue breakdown vs. horizontal bone loss should be approached with caution even though it can bring significant benefits in terms of periodontal recovery and long-term success. We used the finite element method (FEM) to simulate various clinical scenarios regarding the periodontal involvement: healthy with no horizontal bone loss, moderate periodontal damage (33\%) and severe horizontal bone loss (66\%). Afterwards, forces of different magnitudes $(0.25 \mathrm{~N}, 1 \mathrm{~N}, 3 \mathrm{~N}$, and $5 \mathrm{~N})$ were applied in order to observe the behavioral patterns. Through mathematical modeling, we recorded the maximum equivalent stresses ( $\sigma$ ech), the stresses on the direction of force application $(\sigma \mathrm{c})$ and the displacements produced $(\mathrm{f})$ in the whole tooth-periodontal ligament-alveolar bone complex with various degrees of periodontal damage. The magnitude of lingualization forces in the lower anterior teeth influences primarily the values of equivalent tension, then those of the tensions in the direction in which the force is applied, and lastly those of the displacement of the lower central incisor. However, in the case of the lower lateral incisor, it influences primarily the values of the tensions in the direction in which the force is applied, then those of equivalent tensions, and lastly those of displacement. Anatomical particularities should also be considered since they may contribute to increased periodontal risk in case of lingualization of the LLI compared to that of the LCI, with a potential emergence of the "wedge effect". To minimize periodontal hazards, the orthodontic force applied on anterior teeth with affected periodontium should not exceed $1 \mathrm{~N}$.

Keywords: FEM; orthodontic treatment; periodontitis; periodontal disease; FEA; lingualization

\section{Introduction}

Orthodontic treatment in adults is becoming increasingly sought after, but this brings additional issues that have to be properly addressed as the prevalence of periodontal disease increases with age. Bone loss induced by periodontitis occurs when the periodontal tissues are overwhelmed by external forces and are no longer able to compensate for the loss of equilibrium and is associated with malposition of teeth: flaring (especially in anterior teeth), spacing, extrusion, and rotation [1]. Orthodontic treatment of patients with periodontal pathologies can bring significant benefits in terms of periodontal recovery and long-term success, but at the same time it involves a number of precautions [2]. 
Periodontal patients seeking an orthodontic specialist usually deal with major aesthetic and, in particular, functional problems.

Significant tipping of dental units, most often encountered in incisors, leads to an increase in compressive stress while tensile stress decreases [3,4]. Together with increase of compressive stress, a change in the maximum concentration of forces appears, which moves from the central radicular area to the apical lingual area; at the same time, the area of maximum tensile stress moves from the middle of the root to the vestibular cervical area [5]. This is of particular importance in the context of a patient with periodontal damage because it requires, more often than not, the lingualization of the frontal maxillary and mandibular groups, which have become vestibularized as a consequence of the loss of support periodontium.

The finite element method (FEM) is an analysis used to calculate stress and loads in complex structures that is currently widely adopted in biomechanics and the study of the behavior of biological structures [6]. The principle of this method is based on the division of a complex, difficult to analyze structure into smaller, simpler structures called elements. The latter are assigned properties (elasticity modulus, Poisson's ratio, etc.) that describe physical behavior upon the application of an external load (e.g., mastication forces, an orthodontic force, etc.) or upon position modification [7]. All individual elements are connected by nodes that form a coherent network. In this manner, one can compute the response to stress and load using a computer algorithm [8]. Although introduced in research only a few decades ago, the finite element method (FEM) is still a cuttingedge technique. Advanced technologies in creating mathematical models that simulate reality and the continued optimization of biomechanical perimeters allow for high-accuracy analysis, eliminating, to an ever-increasing extent, the likelihood of error.

In the field of dentistry, the finite element method finds its applicability especially in the field of biomechanics. It allows high fidelity analyses of certain stresses on the odontoperiodontal complex while at the same time being a totally noninvasive technique $[9,10]$.

When applying a force of $1 \mathrm{~N}$ to the upper incisors in the lingual direction, Kanjanaouthaia et al. observed that, if the incisors had a more pronounced inclination, the stress was mainly concentrated in the apical area [11]. Orthodontic tooth movement and the physiological rebound of periodontal tissues has a quasi-logarithmic increase that is highly suggestive of the viscoelastic properties of the periodontium, and this behavior should be analyzed in future studies [12]. When coupled with counter-rotation and counter-tipping moments, Jain et al. found that stress was distributed approximately evenly along the desmodontium. In addition, an increased concentration of forces was observed in the furcation area of the posterior teeth in the case of forces applied parallel to the long axis of the teeth. Therefore, the translational movement illustrated a relatively equal distribution of stress, decreasing the probability of root resorption [13].

In FEM analysis, the simulation of materials with complex geometry and dimensions requires the determination of plastic, elastic and viscoelastic properties [14,15]. The determination of stress and tension in the periodontium for various types of dental movements can be determined through linear or nonlinear simulations, the latter being introduced recently and still insufficiently validated in the field of orthodontics [12]. In these circumstances, it is mandatory to carry out a rigorous analysis of the behavior of periodontal tissues under the action of orthodontic forces, in order to establish the indications and, more importantly, contraindications and limits of orthodontic treatment in the case of periodontal disease.

This research aimed to evaluate comparatively the effect of forces with different magnitudes on tissues with different degrees of periodontal damage, moderate $(33 \%)$ and severe $(66 \%)$, compared to unaffected periodontium, while trying to establish a series of recommendations with practical applicability during orthodontic management, with predictable results, in patients that suffer from reduction of bone capital, in the context of a complex oral rehabilitation. The purpose of this study was also to identify potential periodontal hazards that may occur and have not yet been clinically identified. 
The objectives were to monitor the maximum equivalent stresses in the whole toothperiodontal ligament-alveolar bone complex with various degrees of periodontal damage, to evaluate the maximum stresses that occur in the direction of force application and to assess quantitatively and comparatively the dental displacements produced in different clinical scenarios reproduced through mathematical modeling. Further, we determined whether, due to the morphological features of the frontal teeth, they may behave differently under stresses with forces of equal magnitudes in the same context of periodontal damage.

\section{Materials and Methods}

The current research using finite elements involved the realization of three-dimensional models that included the creation of a lower frontal group consisting of four incisors with and without periodontal damage. The dimensions of the teeth, thickness of the periodontal ligament, and specific morphological elements were taken from the literature [16].

The anatomical features were reproduced in the mathematical simulation using a real-scale Nissin didactic model with periodontal damage (Nissin Dental Products ${ }^{\circledR}$ Inc., Kyoto, Japan). During modeling, the following considerations were taken into account: the geometry and morphology of teeth; periodontal structures and dental arches; the physical properties of teeth, periodontal ligament, and alveolar bone; and the magnitude and direction of the force used to simulate orthodontic stress on patients with periodontal damage compared to patients with unaffected periodontium. The application point of the force was set on the center of the facial surface of each tooth. All forces with different magnitudes were applied to each individual tooth.

During the construction of the tooth-periodontal ligament-alveolar bone model we considered from the beginning that the three component elements of the complex have linear elasticity and isotropic properties of the same quality [17]. The definition of the properties and the design of the dental mathematical model was done using the computerassisted design (CAD) program Catia V5R19 (Dassault Systèmes ${ }^{\circledR}$, Velizy-Villacoublay France), based on the dimensions and morphology elements taken from the literature [16]. Table 1 summarizes the tooth dimensions that were used.

Table 1. Tooth dimensions [16].

\begin{tabular}{ccc}
\hline & Lower Central Incisor (LCI) & Lower Lateral Incisor (LLI) \\
\hline Crown length & $9 \mathrm{~mm}$ & $9.5 \mathrm{~mm}$ \\
Root length & $12.5 \mathrm{~mm}$ & $14 \mathrm{~mm}$ \\
Total length & $21.5 \mathrm{~mm}$ & $23.5 \mathrm{~mm}$ \\
M-D crown diameter & $5 \mathrm{~mm}$ & $5.5 \mathrm{~mm}$ \\
M-D crown diameter at cervical level & $3.5 \mathrm{~mm}$ & $4 \mathrm{~mm}$ \\
F-O crown diameter & $6 \mathrm{~mm}$ & $6.5 \mathrm{~mm}$ \\
F-O crown diameter at cervical level & $5.3 \mathrm{~mm}$ & $5.8 \mathrm{~mm}$ \\
\hline
\end{tabular}

M-D = mesio-distal; F-O = facial-oral; $\mathrm{LCI}$ = lower central incisor; LLI = lower lateral incisor.

\subsection{Analysis Model}

The stages of preparing the analysis model follow. We first define the analysis model, which involves identifying the shape and geometric dimensions of the structures to be modeled (in our particular case teeth and periodontal structures), constraints induced by the connections with adjacent elements, external loads, and material characteristics. In the next step, we describe the analysis model; the geometric shape and the dimensions of the analysis model are identical to those of the 3D structure of the assembly to be analyzed, associating the limit conditions (primary stability of monoradicular teeth) and loading the model with forces of various magnitudes and directions [17]. In Figure 1, we depict the modeling of the mandibular anterior arch under three scenarios: no periodontal damage and $33 \%$ and $66 \%$ bone loss. 


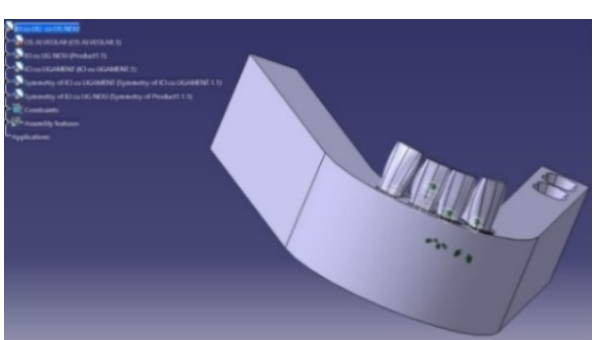

(a)

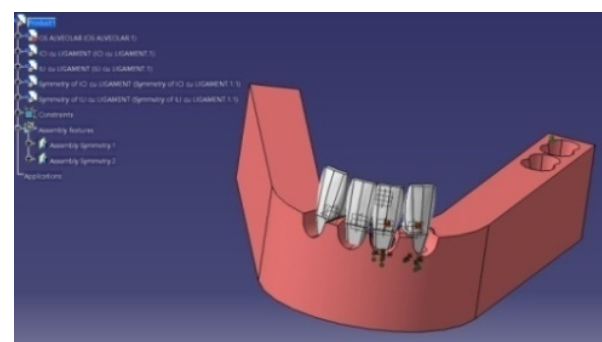

(b)

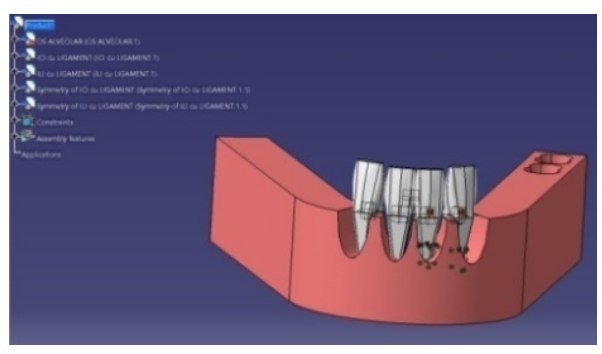

(c)

Figure 1. (a) Mandibular model with no periodontal damage, (b) mandibular model with $33 \%$ periodontal damage, and (c) $66 \%$ periodontal damage.

Finally, the characteristics of the material were established using data from the literature (Table 2) [18-20]:

Table 2. Material characteristics.

\begin{tabular}{cccc}
\hline Material & Young's Modulus & Poisson's Coefficient & References \\
\hline Tooth & $20 \mathrm{GPa}$ & 0.30 & Caballero et al. 2015 [18] \\
Cortical bone & $13.7 \mathrm{GPa}$ & 0.30 & Kurgan et al. 2014 [19] \\
Spongy bone & $345 \mathrm{MPa}$ & 0.30 & Caballero et al. 2015 [18] \\
Periodontal ligament & $0.71 \mathrm{MPa}$ & 0.40 & Xia et al. 2013 [20] \\
\hline
\end{tabular}

Using the mathematical model of the mandibular structure and the anterior teeth, we recorded the maximum equivalent stresses ( $\sigma$ ech) that occurred at the level of the whole complex, the stresses in the direction of force application $(\sigma \mathrm{c})$, and the displacements $(\mathrm{f})$ consequential to the applied forces.

\subsection{Statistical Analyses}

Statistical analyses were performed with SPSS 24.0 for Windows (IBM Corporation, North Castle Drive, Armonk, NY, USA). Between-treatment comparisons were analyzed with the nonparametric multivariate Kruskal-Wallis test, and correlations were calculated with Spearman's rank-order test. Graphs were generated using STATA 16.1 (StataCorp LLC., College Station, TX, USA). A $p$-value less than 0.05 was considered statistically significant.

\section{Results}

The results obtained in the previously described clinical scenarios and translated into a mathematical model are summarized in the tables below for the lower central incisor (Table 3) and for the lower lateral incisor (Table 4).

Representative iconographic elements in various scenarios of force application and lingualization of the lower central incisor (LCI) using a 1 and $3 \mathrm{~N}$ force are shown in Figures $2-4$ and Figures 5-7, respectively. Figures 8-10 depict representative iconographic elements for lingualization of the lower lateral incisor (LLI) using a $1 \mathrm{~N}$ force and Figures 11 and 12 depict application of a $3 \mathrm{~N}$ force.

In the case of no HBL (Figure 2), the $1 \mathrm{~N}$ force is evenly distributed along the central region of the root of the LCI, both on the buccal and on the lingual areas. This area becomes narrower in the $33 \%$ bone loss simulation, particularly close to the center of rotation of the tooth (Figure 3), and finally as bone loss reaches $66 \%$ the tooth inclines lingually and the area of maximum tension is in the vestibular apical third (Figure 4).

When a force of greater magnitude is applied, $3 \mathrm{~N}$, we observed that in case of a healthy periodontium the tissues are able to absorb and compensate for the increased strain, and the areas of maximum stress remain the same as in the case of a $1 \mathrm{~N}$ force. However, lingualization of the LCI occurs even at a moderate periodontal bone loss of $33 \%$; in this case the tissues are no longer able to compensate and the areas of maximum 
stress are mainly concentrated on the buccal apical third of the root and to a lesser degree in the lingual area (Figures 5 and 6). In Figure 7, we observe a severe lingualization of the LCI, the stress being concentrated only in the apical vestibular area. The LLI has similar patterns of stress distribution and movement to the LCI and, as the periodontal tissue loss aggravates, so does the lingualization of the teeth.

Table 3. Simulation of lingualization in the lower central incisor according to the applied force and extent of periodontal damage.

\begin{tabular}{|c|c|c|c|}
\hline \multirow[t]{2}{*}{ Applied Force } & \multicolumn{3}{|c|}{$\begin{array}{c}\text { Extent of Periodontal Damage } \\
\text { (HBL) }\end{array}$} \\
\hline & No HBL & $33 \% \mathrm{HBL}$ & $66 \% \mathrm{HBL}$ \\
\hline \multirow{3}{*}{$0.25 \mathrm{~N}$} & $\sigma$ ech $=0.0271 \mathrm{MPa}$ & $\sigma$ ech $=0.73 \mathrm{MPa}$ & $\sigma$ ech $=2.1 \mathrm{MPa}$ \\
\hline & $\sigma \mathrm{c}=0.0272 \mathrm{MPa}$ & $\sigma \mathrm{c}=0.751 \mathrm{MPa}$ & $\sigma \mathrm{c}=2.16 \mathrm{MPa}$ \\
\hline & $\mathrm{f}=0.00468 \mathrm{~mm}$ & $\mathrm{f}=0.124 \mathrm{~mm}$ & $\mathrm{f}=1.12 \mathrm{~mm}$ \\
\hline \multirow{3}{*}{$1 \mathrm{~N}$} & $\sigma \mathrm{ech}=1.37 \mathrm{MPa}$ & $\sigma \mathrm{ech}=2.92 \mathrm{MPa}$ & $\sigma \mathrm{ech}=8.43 \mathrm{MPa}$ \\
\hline & $\sigma \mathrm{c}=1.38 \mathrm{MPa}$ & $\sigma \mathrm{c}=2.98 \mathrm{MPa}$ & $\sigma \mathrm{c}=8.67 \mathrm{MPa}$ \\
\hline & $\mathrm{f}=0.208 \mathrm{~mm}$ & $\mathrm{f}=0.497 \mathrm{~mm}$ & $\mathrm{f}=4.48 \mathrm{~mm}$ \\
\hline \multirow{3}{*}{$3 \mathrm{~N}$} & $\sigma \mathrm{ech}=4.12 \mathrm{MPa}$ & $\sigma$ ech $=8.74 \mathrm{MPa}$ & $\sigma \mathrm{ech}=25.3 \mathrm{MPa}$ \\
\hline & $\sigma \mathrm{c}=4.15 \mathrm{MPa}$ & $\sigma \mathrm{c}=8.91 \mathrm{MPa}$ & $\sigma \mathrm{c}=26 \mathrm{MPa}$ \\
\hline & $\mathrm{f}=0.626 \mathrm{~mm}$ & $\mathrm{f}=1.49 \mathrm{~mm}$ & $\mathrm{f}=13.4 \mathrm{~mm}$ \\
\hline \multirow{3}{*}{$5 \mathrm{~N}$} & $\sigma$ ech $=6.86 \mathrm{MPa}$ & $\sigma$ ech $=14.6 \mathrm{MPa}$ & $\sigma$ ech $=42.2 \mathrm{MPa}$ \\
\hline & $\sigma \mathrm{c}=6.94 \mathrm{MPa}$ & $\sigma \mathrm{c}=14.9 \mathrm{MPa}$ & $\sigma \mathrm{c}=43.3 \mathrm{MPa}$ \\
\hline & $\mathrm{f}=1.04 \mathrm{~mm}$ & $\mathrm{f}=2.49 \mathrm{~mm}$ & $\mathrm{f}=22.4 \mathrm{~mm}$ \\
\hline
\end{tabular}

Table 4. Simulation of lingualization in the LLI.

\begin{tabular}{|c|c|c|c|}
\hline \multirow[t]{2}{*}{ Applied Force } & \multicolumn{3}{|c|}{$\begin{array}{l}\text { Extent of Periodontal Damage } \\
\text { (HBL) }\end{array}$} \\
\hline & No HBL & $33 \% \mathrm{HBL}$ & $66 \% \mathrm{HBL}$ \\
\hline \multirow{3}{*}{$0.25 \mathrm{~N}$} & $\sigma \mathrm{ech}=1.03 \mathrm{MPa}$ & $\sigma$ ech $=1.4 \mathrm{MPa}$ & $\sigma$ ech $=7.67 \mathrm{MPa}$ \\
\hline & $\sigma \mathrm{c}=0.455 \mathrm{MPa}$ & $\sigma \mathrm{c}=0.697 \mathrm{MPa}$ & $\sigma \mathrm{c}=3.79 \mathrm{MPa}$ \\
\hline & $\mathrm{f}=0.065 \mathrm{~mm}$ & $\mathrm{f}=0.198 \mathrm{~mm}$ & $\mathrm{f}=2.35 \mathrm{~mm}$ \\
\hline \multirow{3}{*}{$1 \mathrm{~N}$} & $\sigma \mathrm{ech}=4.16 \mathrm{MPa}$ & $\sigma$ ech $=5.59 \mathrm{MPa}$ & $\sigma$ ech $=30.7 \mathrm{MPa}$ \\
\hline & $\sigma \mathrm{c}=1.86 \mathrm{MPa}$ & $\sigma \mathrm{c}=2.79 \mathrm{MPa}$ & $\sigma \mathrm{c}=15.2 \mathrm{MPa}$ \\
\hline & $\mathrm{f}=0.26 \mathrm{~mm}$ & $\mathrm{f}=0.794 \mathrm{~mm}$ & $\mathrm{f}=9.41 \mathrm{~mm}$ \\
\hline \multirow{3}{*}{$3 \mathrm{~N}$} & $\sigma \mathrm{ech}=12.3 \mathrm{MPa}$ & $\sigma$ ech $=16.8 \mathrm{MPa}$ & $\sigma$ ech $=92.1 \mathrm{MPa}$ \\
\hline & $\sigma \mathrm{c}=5.39 \mathrm{MPa}$ & $\sigma \mathrm{c}=8.37 \mathrm{MPa}$ & $\sigma \mathrm{c}=45.5 \mathrm{MPa}$ \\
\hline & $\mathrm{f}=0.782 \mathrm{~mm}$ & $\mathrm{f}=2.38 \mathrm{~mm}$ & $\mathrm{f}=28.3 \mathrm{~mm}$ \\
\hline \multirow{3}{*}{$5 \mathrm{~N}$} & $\sigma \mathrm{ech}=20.5 \mathrm{MPa}$ & $\sigma \mathrm{ech}=28 \mathrm{MPa}$ & $\sigma \mathrm{ech}=154 \mathrm{MPa}$ \\
\hline & $\sigma \mathrm{c}=8.92 \mathrm{MPa}$ & $\sigma \mathrm{c}=14 \mathrm{MPa}$ & $\sigma \mathrm{c}=75.9 \mathrm{MPa}$ \\
\hline & $\mathrm{f}=1.3 \mathrm{~mm}$ & $\mathrm{f}=3.97 \mathrm{~mm}$ & $\mathrm{f}=47.1 \mathrm{~mm}$ \\
\hline
\end{tabular}




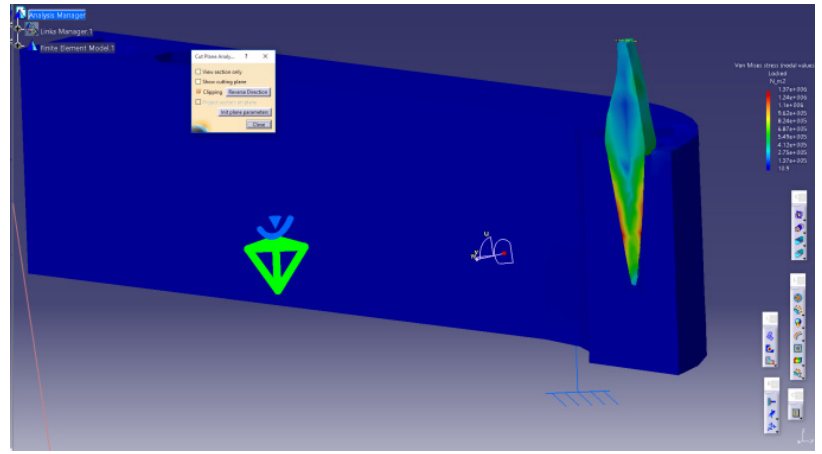

(a)

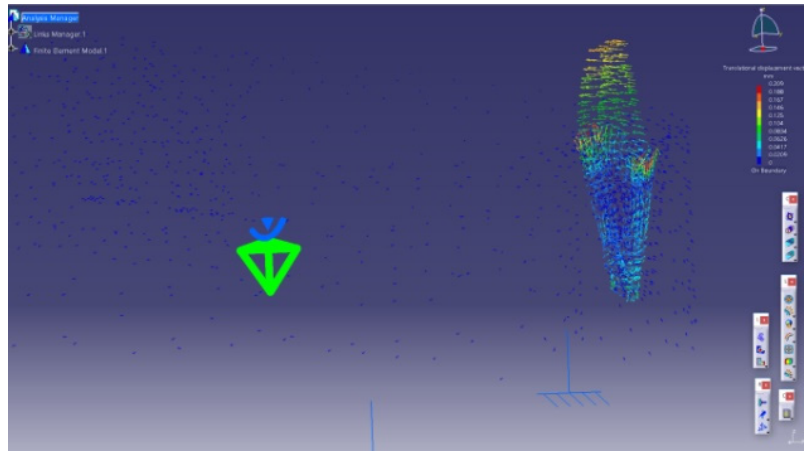

(b)

Figure 2. Lingualization of the LCI using a $1 \mathrm{~N}$ force: (a) von Mises tensions, no HBL; (b) tooth movement obtained, no HBL.

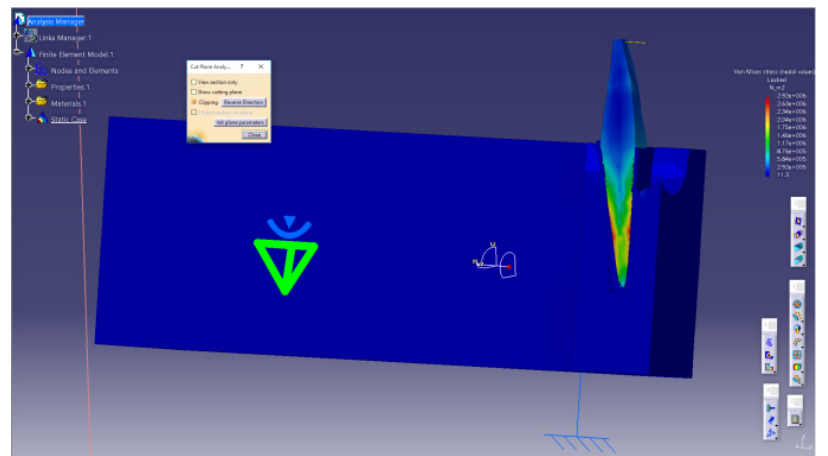

(a)

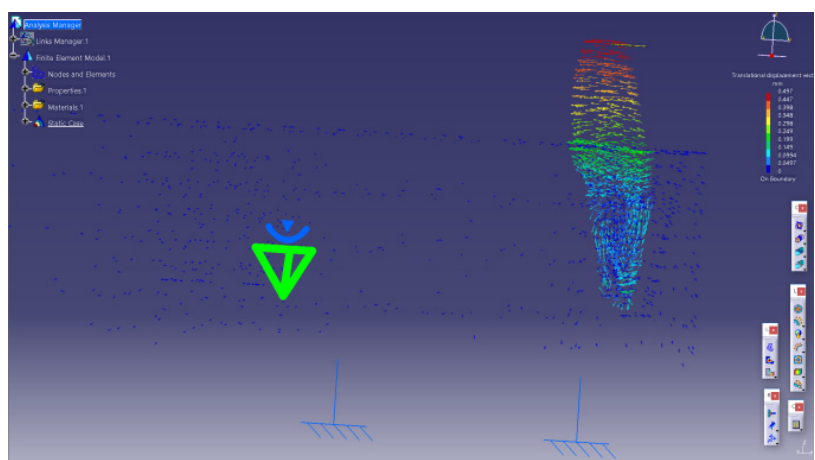

(b)

Figure 3. Lingualization of the LCI using a $1 \mathrm{~N}$ force: (a) von Mises tensions, 33\% HBL; (b) tooth movement, 33\% HBL.

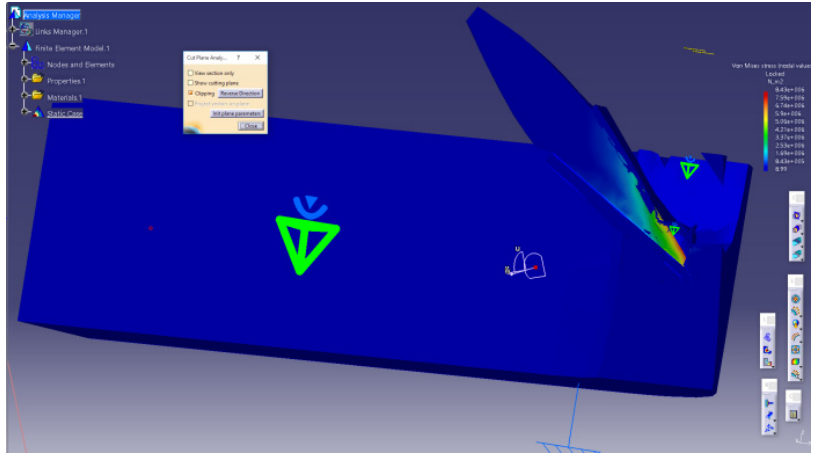

(a)

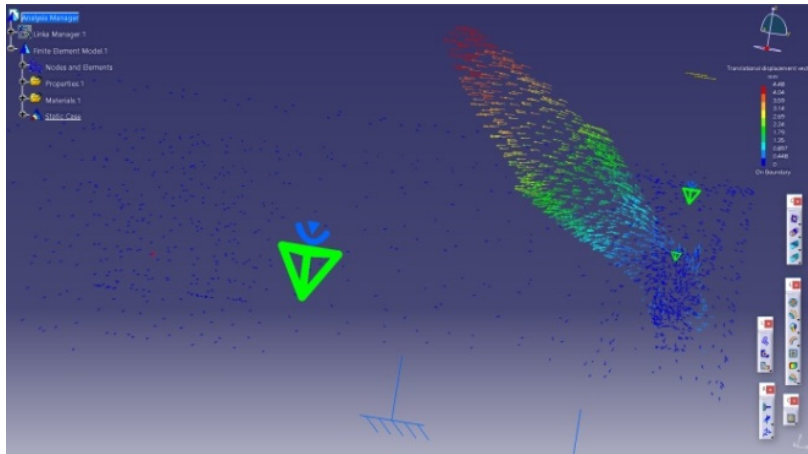

(b)

Figure 4. Lingualization of the LCI using a $1 \mathrm{~N}$ force: (a) von Mises tensions, 66\% HBL; (b) tooth movement, $66 \% \mathrm{HBL}$.

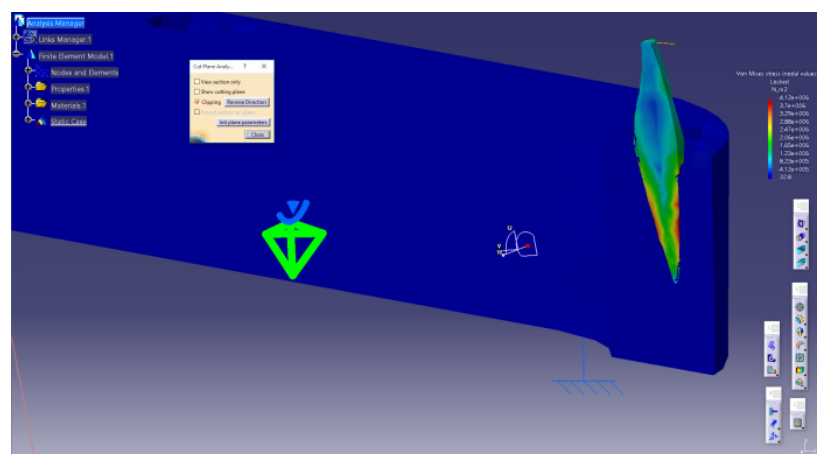

(a)

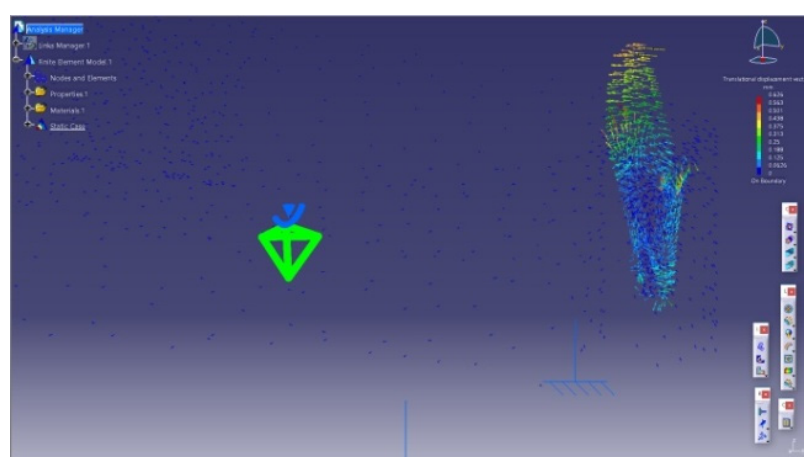

(b)

Figure 5. Lingualization of the LCI using a $3 \mathrm{~N}$ force: (a) von Mises tensions, no HBL; (b) tooth movement obtained, no HBL. 


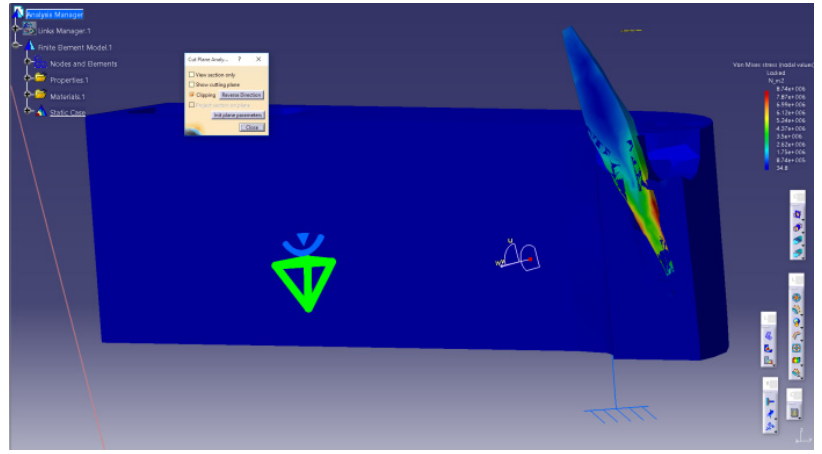

(a)

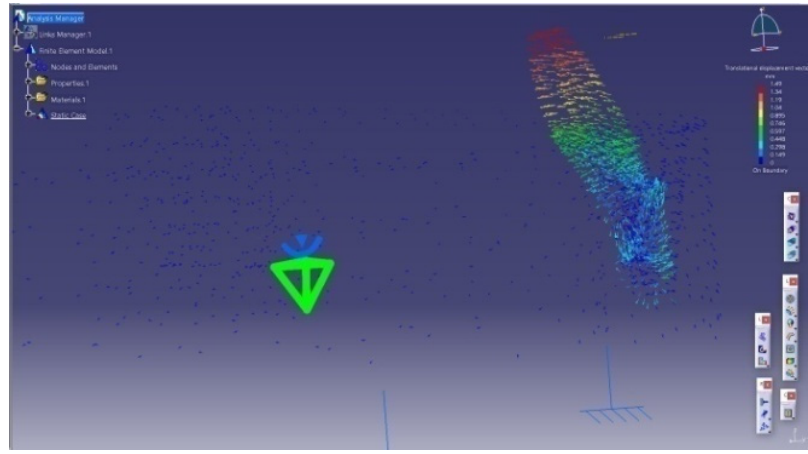

(b)

Figure 6. Lingualization of the lower LCI using a $3 \mathrm{~N}$ force: (a) von Mises tensions, 33\% HBL; (b) tooth movement, 33\% HBL.

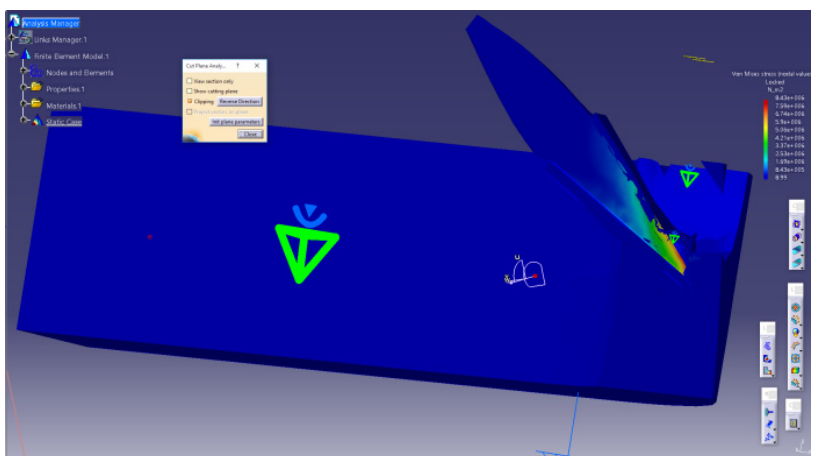

(a)

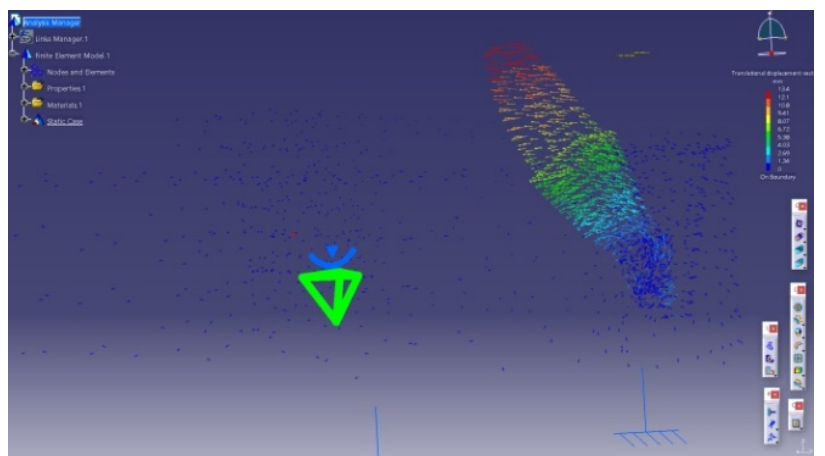

(b)

Figure 7. Lingualization of the LCI using a $3 \mathrm{~N}$ force: (a) von Mises tensions, $66 \%$ HBL; (b) tooth movement, $66 \%$ HBL.

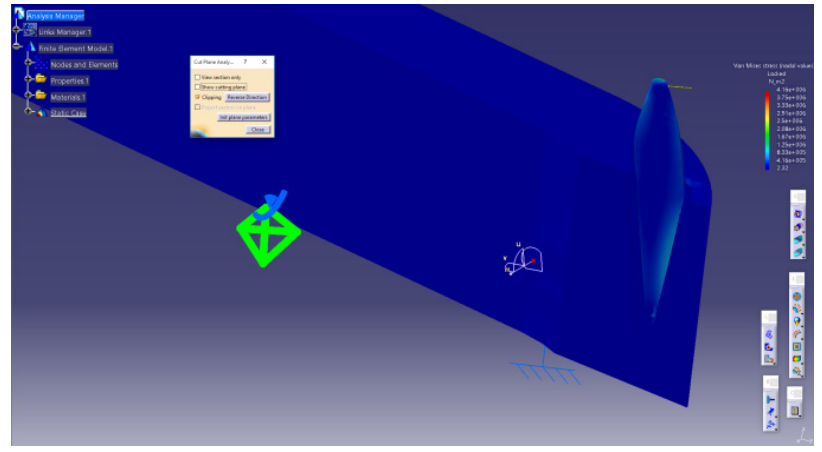

(a)

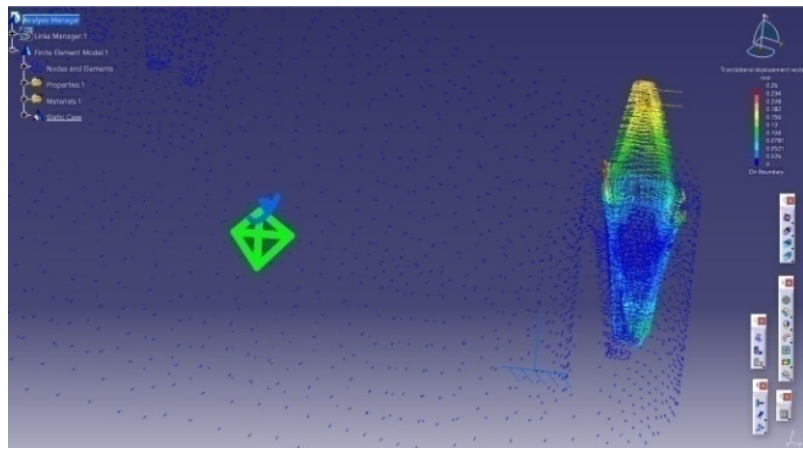

(b)

Figure 8. Lingualization of the LLI using a $1 \mathrm{~N}$ force: (a) von Mises tensions, no HBL; (b) tooth movement obtained, no HBL.

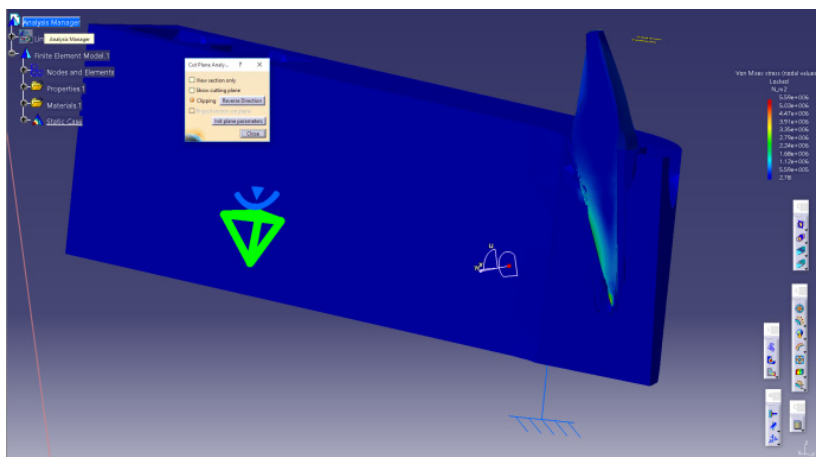

(a)

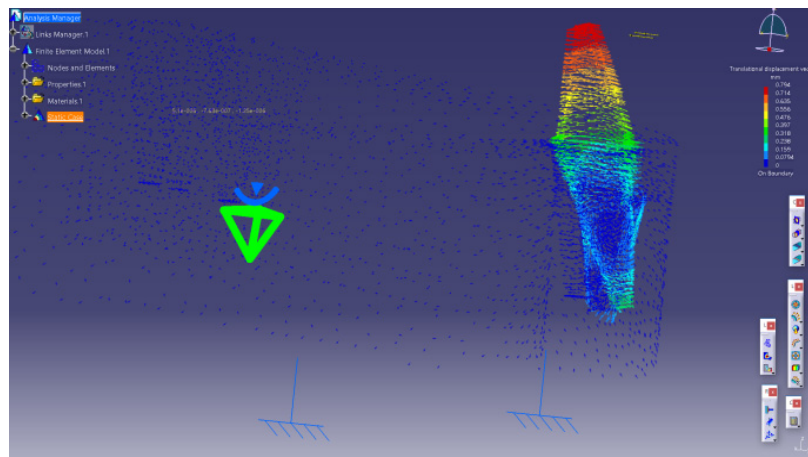

(b)

Figure 9. Lingualization of the LLI using a $1 \mathrm{~N}$ force: (a) von Mises tensions, 33\% HBL; (b) tooth movement, 33\% HBL. 


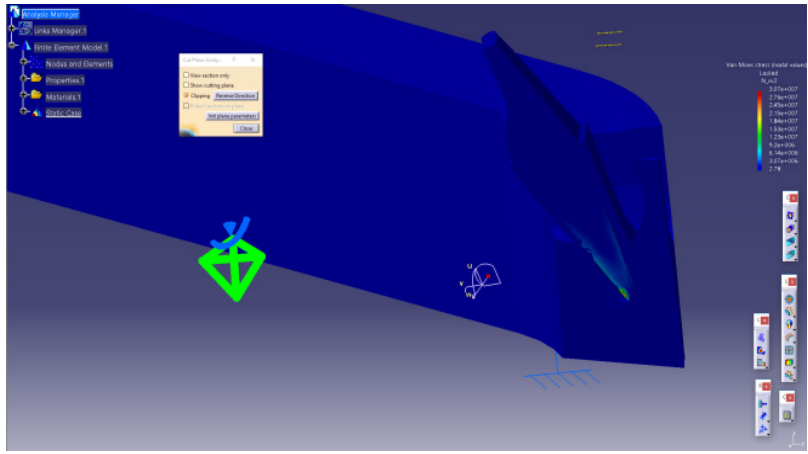

(a)

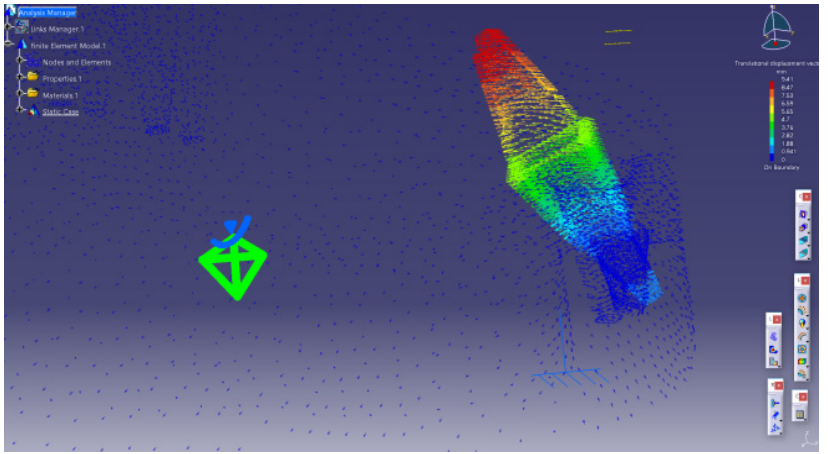

(b)

Figure 10. Lingualization of the LLI using a $1 \mathrm{~N}$ force: (a) von Mises tensions, $66 \% \mathrm{HBL}$; (b) tooth movement, $66 \% \mathrm{HBL}$.

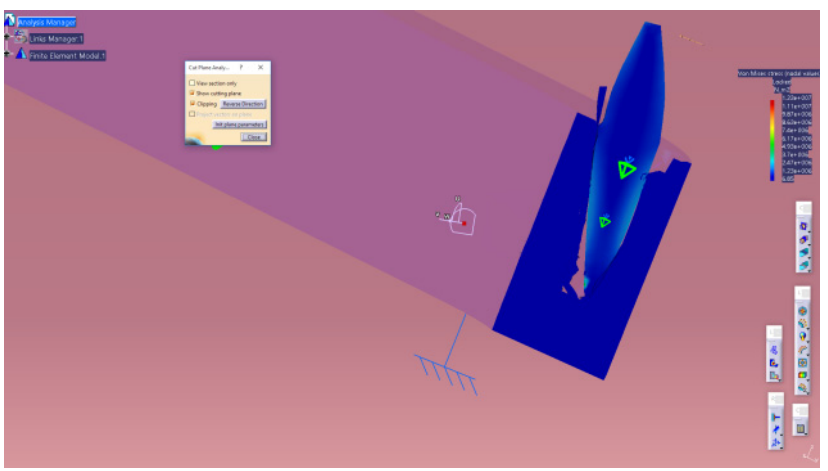

(a)

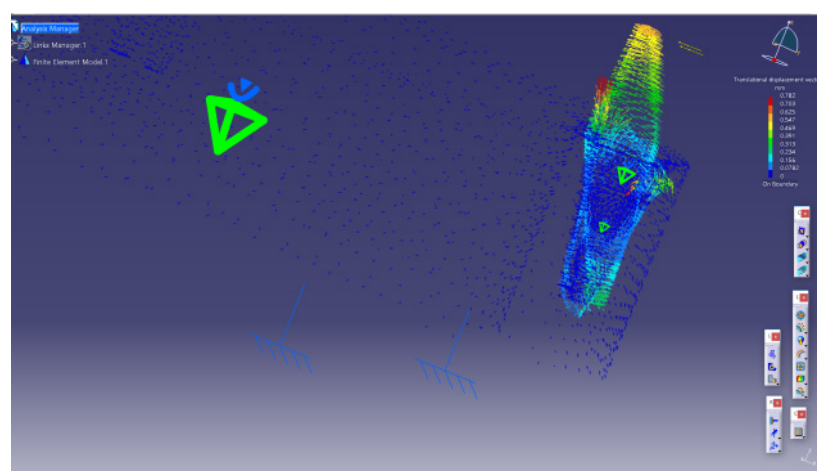

(b)

Figure 11. Lingualization of the LLI using a $3 \mathrm{~N}$ force: (a) von Mises tensions, no HBL; (b) tooth movement obtained, no HBL.

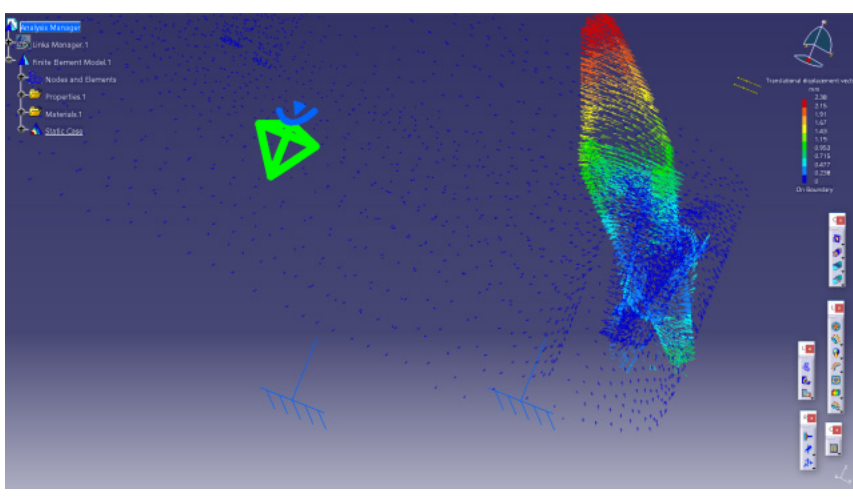

(a)

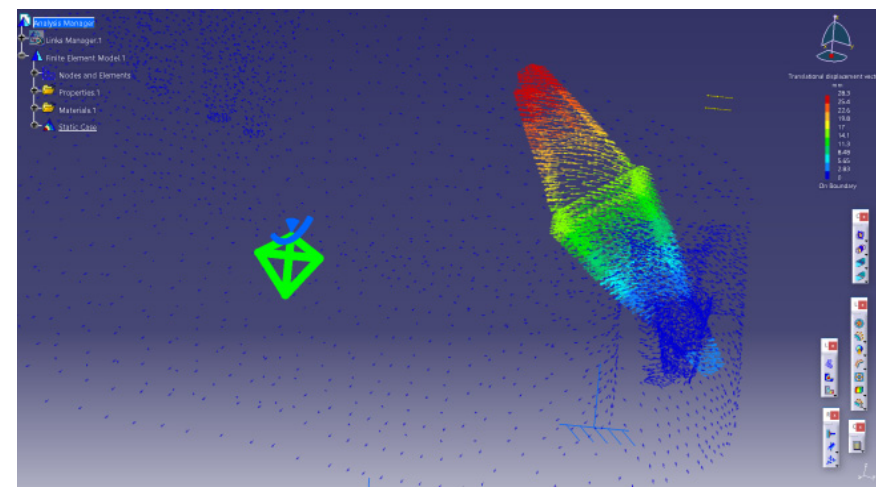

(b)

Figure 12. Lingualization of the LLI using a $3 \mathrm{~N}$ force: (a) tooth movement, 33\% HBL; (b) tooth movement, $66 \% \mathrm{HBL}$.

\subsection{Lower Central Incisor (LCI)}

3.1.1. Predictive Factors in the Modification of the Equivalent Tension Values in the Tooth-Periodontal Ligament-Alveolar Bone Complex ( $\sigma$ ech)

The $\sigma$ ech values show linear growth, based on the force applied in the case of healthy periodontium and when the damage is up to $33 \%$. In the case of $66 \%$ periodontal damage, the growth is exponential. The values of $\sigma$ ech differ significantly depending on the applied force $(\mathrm{H}=10.665, p=0.009,95 \% \mathrm{CI})$. Using multivariate analysis, we subsequently analyzed the importance of the parameters that influence $\sigma$ ech tension values, the independent variables included were the applied force and the extent of the periodontium damage. The analysis of the results of the multiple correlation in the case of lower central incisor 
lingualization highlights that both the applied force and the degree of damage have a major effect on $\sigma$ ech $(\beta f=0.65, p=0.003$, $\beta$ Af.P $=0.56, p=0.008)$ (Table 5).

Table 5. Results of the multivariate analysis-partial correlation coefficient $\sigma$ ech, $\sigma \mathrm{c}$, and f.

\begin{tabular}{|c|c|c|c|c|c|c|}
\hline & $\begin{array}{c}\text { Correlation } \\
\text { Coefficient (Beta) }\end{array}$ & $\begin{array}{l}\text { Std. Err. } \\
\text { (Beta) }\end{array}$ & B & Std. Err. B & $\mathbf{t}$ & $\begin{array}{c}p \\
95 \% \mathrm{CI}\end{array}$ \\
\hline \multicolumn{7}{|l|}{$\begin{array}{c}\text { Partial correlation } \sigma \text { ech } \\
\text { vs. }\end{array}$} \\
\hline Intercept & & & -837.143 & 249.0675 & -3.36111 & 0.008 \\
\hline Applied force & 0.659321 & 0.166887 & 4.260 & 1.0783 & 3.95071 & 0.003 \\
\hline Periodontal damage & 0.560924 & 0.166887 & 8.207 & 2.4416 & 3.36111 & 0.008 \\
\hline \multicolumn{7}{|l|}{$\begin{array}{c}\text { Partial correlation } \sigma \mathrm{c} \\
\text { vs. }\end{array}$} \\
\hline Intercept & & & -862.383 & 256.3378 & -3.36424 & 0.008 \\
\hline Applied force & 0.656882 & 0.167272 & 4.358 & 1.1098 & 3.92702 & 0.003 \\
\hline Periodontal damage & 0.562749 & 0.167272 & 8.454 & 2.5129 & 3.36427 & 0.008 \\
\hline \multicolumn{7}{|l|}{$\begin{array}{c}\text { Partial correlation } \mathrm{f} \\
\text { vs. }\end{array}$} \\
\hline Intercept & & & -503.908 & 171.6010 & -2.93651 & 0.016 \\
\hline Applied force & 0.485140 & 0.208293 & 1.730 & 0.7429 & 2.32912 & 0.044 \\
\hline Periodontal damage & 0.611691 & 0.208293 & 4.940 & 1.6822 & 2.93669 & 0.016 \\
\hline
\end{tabular}

* CI, confidence interval; Std. Err., standard error.

3.1.2. Predictive Factors in the Modification of the Tension Values in the Direction of an Applied Perpendicular Force to the Tooth's Vestibular Surface $(\sigma \mathrm{c})$

Using multivariate analysis, we determined the influence of $\sigma \mathrm{c}$ tension values with applied force and the extent of the periodontium damage as independent variables. As such, the applied force had a significant impact on the value of $\sigma \mathrm{c}$ for the lower central incisors $(\beta \mathrm{f}=0.65, p=0.003)$, with periodontal damage having a significant influence ( $\beta$ AfP $=0.56, p=0.008)$ (Table 4). Correlation analysis showed that the applied force had a major impact on $f(\beta \mathrm{f}=0.48, p=0.044)$, as did the presence of periodontal disease $(\beta$ Af.P $=0.61, p=0.016)$ (Table 5$)$.

\subsubsection{Correlation of $\sigma$ ech, $\sigma \mathrm{c}$, and $\mathrm{f}$ Based on the Value of the Applied Force}

Figure 13 shows that the equivalent tension in the tooth-periodontal ligament-alveolar bone complex ( $\sigma$ ech $-\mathrm{r}=0.65$ ) was most affected by the magnitude of the applied force; close behind was tension value in the direction in which the force is applied $(\sigma \mathrm{c}-\mathrm{r}=0.65)$. The recorded displacement values ( $f-r=0.48$ ) were not affected significantly by the magnitude of applied force.

\subsection{Lower Lateral Incisor (LLI)}

3.2.1. Equivalent Tension in the Tooth-Periodontal Ligament-Alveolar Bone Complex $(\sigma \mathrm{ech})$

For both lower central and lateral incisors, the $\sigma$ ech values showed linear growth, depending on the force applied when the periodontium was healthy or affected $33 \%$. If the periodontium was affected $66 \%$, the increase of $\sigma$ ech showed exponential evolution. Correlation analysis showed that both the magnitude of the applied force $(\beta \mathrm{f}=0.56$, $p=0.018)$ and the extent to which the periodontium is affected ( $\beta$ AfP $=0.57, p=0.017$ ) have a significant impact on the values of $\sigma$ ech for lower lateral incisors (Table 6). 


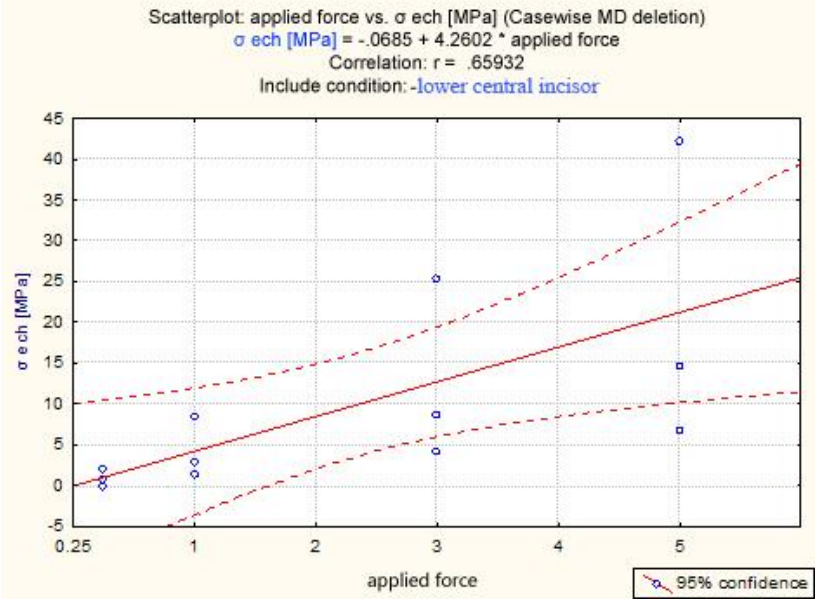

(a)

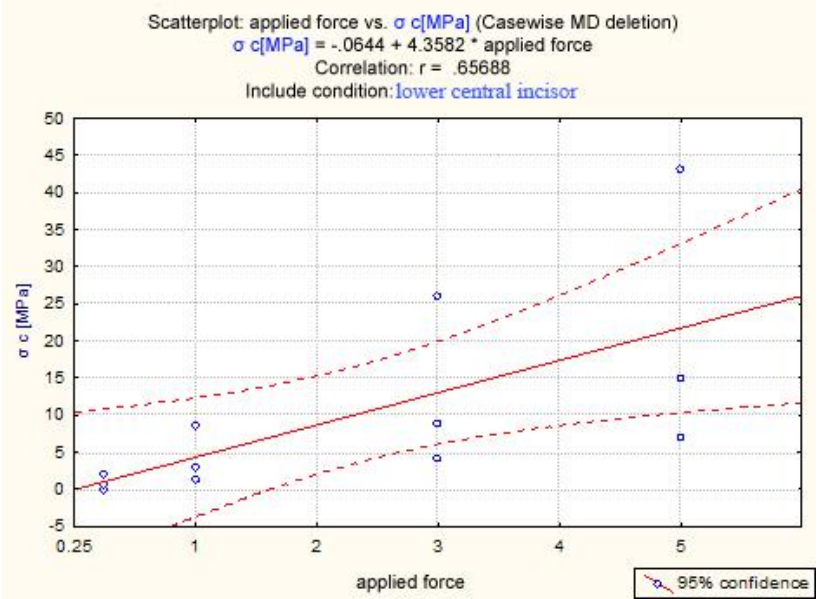

(b)

Scatterplot: applied force vs. $\mathrm{f}$ [mm] (Casewise MD deletion) $f[\mathrm{~mm}]=-.0116+1.7304$ applied force

include Correlation: $r=48514$

clude condition:lower central incisor

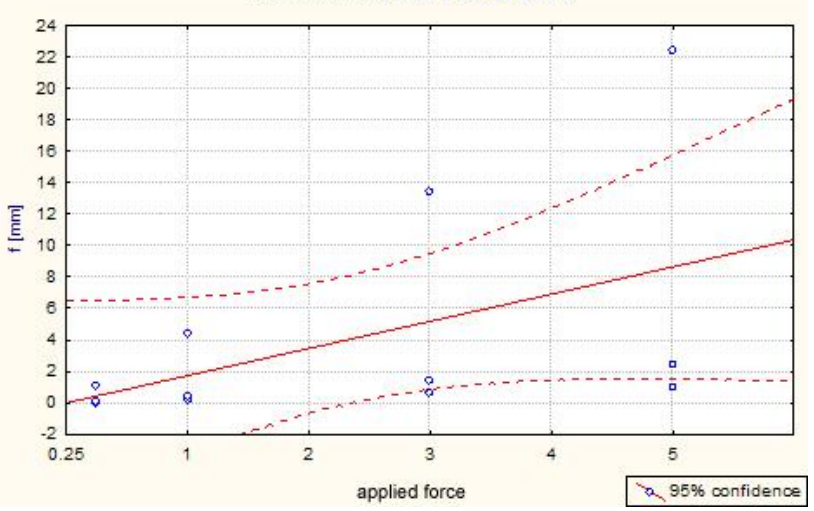

(c)

Figure 13. Regression line for the correlation of (a) $\sigma$ ech, (b) $\sigma \mathrm{c}$, and (c) $\mathrm{f} v \mathrm{vs}$. applied force.

3.2.2. Tension Registered in the Direction of the Applied Force-Perpendicular to the Tooth's Vestibular Surface [ $\sigma \mathrm{c}$ ]

The MULTIVARIATE analysis identified the predictive factors in the changes of the $\sigma$ $c$ tension values on the direction of application of a force perpendicular to the vestibular surface of the tooth. Correlation analysis showed that both the magnitude of the applied force and the extent to which the periodontium is affected have a significant impact on the values of $\sigma$ ech and $\sigma \mathrm{c}(\beta \mathrm{f}=0.56, p=0.018, \beta \mathrm{AfP}=0.57, p=0.017$ and $\beta \mathrm{f}=0.55, p=0.019$, $\beta$ AfP $=0.58, p=0.016$, respectively) (Table 6).

The multivariate analysis revealed the predictive factors in changes of values of displacement as a result of applying a lingualization force. The applied force does not have a significant impact on displacement $\mathrm{f}(\beta \mathrm{f}=0.46, p=0.058)$, but that the extent of periodontal damage significantly influenced displacement $\mathrm{f}(\beta$ Af.P $=0.61, p=0.017)$ (Table 6). 
Table 6. Results of the multivariate analysis-partial correlation coefficient $\sigma$ ech, $\sigma \mathrm{c}$, and f.

\begin{tabular}{|c|c|c|c|c|c|c|}
\hline & $\begin{array}{c}\text { Correlation } \\
\text { Coefficient (Beta) }\end{array}$ & $\begin{array}{l}\text { Std. Err. } \\
\text { (Beta) }\end{array}$ & B & Std. Err. B & $\mathbf{t}$ & $\begin{array}{c}p \\
95 \% \mathrm{CI}\end{array}$ \\
\hline \multicolumn{7}{|l|}{$\begin{array}{l}\text { Partial correlation } \sigma \text { ech } \\
\text { vs. }\end{array}$} \\
\hline Intercept & & & -3142.65 & 1085.324 & -2.89558 & 0.017 \\
\hline Applied force & 0.567328 & 0.197499 & 13.50 & 4.699 & 2.87256 & 0.018 \\
\hline Periodontal damage & 0.571916 & 0.197499 & 30.81 & 10.640 & 2.89580 & 0.017 \\
\hline \multicolumn{7}{|l|}{$\begin{array}{c}\text { Partial correlation } \sigma \mathrm{c} \\
\text { vs. }\end{array}$} \\
\hline Intercept & & & -1577.99 & 535.3633 & -2.94752 & 0.016 \\
\hline Applied force & 0.559729 & 0.197028 & 6.58 & 2.3178 & 2.84086 & 0.019 \\
\hline Periodontal damage & 0.580795 & 0.197028 & 15.47 & 5.2482 & 2.94778 & 0.016 \\
\hline \multicolumn{7}{|l|}{$\begin{array}{c}\text { Partial correlation } \mathrm{f} \\
\text { vs. }\end{array}$} \\
\hline Intercept & & & -1080.60 & 371.9040 & -2.90559 & 0.017 \\
\hline Applied force & 0.460901 & 0.212483 & 3.49 & 1.6101 & 2.16912 & 0.058 \\
\hline Periodontal damage & 0.617439 & 0.212483 & 10.59 & 3.6458 & 2.90583 & 0.017 \\
\hline
\end{tabular}

CI, confidence interval; Std. Err., standard error.

3.2.3. Correlation Analysis of $\sigma$ ech, $\sigma \mathrm{c}$, and $\mathrm{f}$ Based on the Value of Applied Force

None of the analyzed parameters was significantly influenced by the magnitude of the applied force, values of the tension recorded in the direction of force application $(\sigma \mathrm{c}-\mathrm{r}=0.55, p=0.058)$, values of equivalent tension at the level of the tooth-periodontal ligament-alveolar bone complex ( $\sigma$ ech $-\mathrm{r}=0.56, p=0.054$ ), or values of the recorded displacement ( $\mathrm{f}-\mathrm{r}=0.46, p=0.132$ ) (Figure 14).

The values of $\sigma$ ech presented a uniform increase for no periodontal damage group and for the $33 \%$ HBL. However, for the $66 \%$ periodontal damage group, $\sigma$ ech shows an exponential increase. The values of $\sigma \mathrm{c}$ showed the same tendency, but for the $66 \%$ periodontal damage group, the increase was significantly higher compared with the other two groups. Displacement parameter $(f)$ had increased absolute values that were dependent not only on the magnitude of the applied force but also on the degree of HBL.

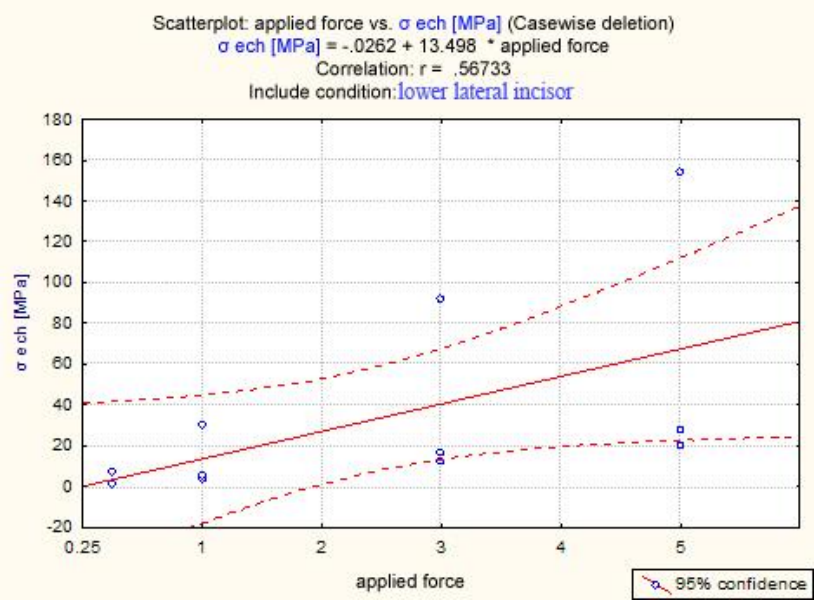

(a)

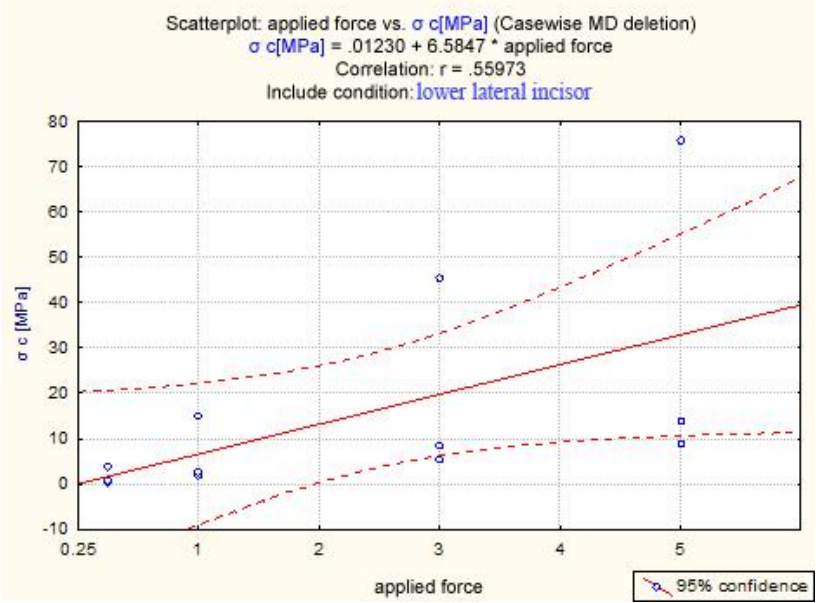

(b)

Figure 14. Cont. 


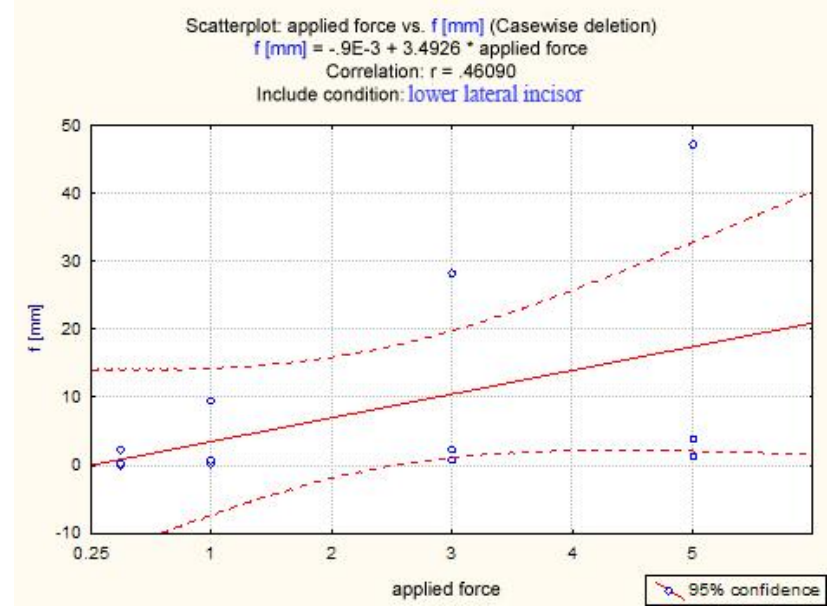

(c)

Figure 14. Regression line of the correlation (a) $\sigma$ ech, (b) $\sigma$ c, and (c) f vs. applied force.

\section{Discussion}

Currently, there is no consensus as to what the optimal force for orthodontic tooth movement should be; however, most agree that it is up to $1 \mathrm{~N}[21,22]$. Although this may be true theoretically, in practice it is difficult to control and assess the precise force applied to every tooth. As the force magnitude increases, so do the potential unwanted side effects such as undesired tooth movements, external apical root resorption, hyalinization, and patient discomfort [21,23,24].

Due to the inconsistencies in the literature and because of the theoretical nature of the study, we considered various force magnitudes in our simulation, up to $5 \mathrm{~N}$, to illustrate the effect on periodontal tissues of different force magnitudes on various scenarios of bone loss. In the case of $1 \mathrm{~N}$ force, we noted that when the profound periodontium tissues are intact, the forces are evenly distributed along the central region of the root of the central lower incisor, both on the buccal and lingual areas. As the periodontal tissues start to break down, the stress concentrates to a narrower area, mostly around the tooth's center of rotation. Finally, as the bone loss reaches $66 \%$ the crown of the tooth is lingualized, while the root is buccally inclined. The area of maximum tension is in the vestibular apical third. Even though in all three scenarios the force magnitude was the same $(1 \mathrm{~N})$, the biomechanical behavior of the tooth was different due to the contrasting periodontal status: intact, moderate, and severe periodontal breakdown. Our results were similar to those found in the literature that considered orthodontic tooth movement on an intact desmodontium and observed that the stresses were concentrated in the apical root area in the case of the application of a purely intrusive, extrusive, or rotational force [25-28]. For the tipping movement, the main stress area was situated at the alveolar crest while for bodily movement, it was throughout the desmodontium [25]. In contrast, others have argued that the morphology of the alveolar bone dictated the stress-strain observations and due to the nonlinear behavior of the desmodontium different areas of compression and tension cannot be detected; thus, light continuous forces are recognized as intermittent by the periodontal ligament [29].

In the case of an affected desmodontium, one study reports results similar to ours in the case of applying a $1 \mathrm{~N}$ force on an incisor and showed that as the severity of the bone loss upsurges the amount of tooth movement increased to a maximum of $2.60 \mathrm{~mm}$ [30].

The lateral lower incisor has similar patterns of stress distribution and movement to the central incisor; as bone loss aggravates, so does the lingualization of the teeth. If the periodontal tissue is intact, it is able to absorb and compensate for the heightened forces to a certain degree, even those exceeding the accepted physiological values for orthodontic tooth movement. However, in the case of a reduced periodontium lingualization is observed, in this case the tissues are no longer able to compensate, and the areas of maximum stress 
are unevenly distributed. Toms et al. considered both linear and nonlinear models of the periodontal ligament of a mandibular premolar and after applying extrusive and tipping forces examined the minimum and maximum principal stresses and von Mises stresses in the desmodontium. When the periodontium was given nonlinear mechanical properties, the stresses were substantially different from the uniform thickness model; in the apical and cervical area the stresses were significantly increased when compared to the linear model [31]. Considering the fact that in our study the periodontium was linear, a nonlinear analysis might yield even more dramatic results in the case of reduced bone level.

Optimal orthodontic movement should be calibrated to the degree of periodontal disease progression. Strain of anterior teeth is reported to be concentrated in the cervical region at the top of the alveolar crest, and it increases even more as the bone level decreases. Moreover, this strain increases even more in subjects with excessively inclined anterior teeth This is a common side effect that is usually addressed during orthodontic therapy of periodontally compromised patients. To avoid the deformation of the alveolar ridge crest in these cases, Ma and Li recommend displacements of less than $0.18 \mathrm{~mm}$ for normal alveolar bone, $0.15 \mathrm{~mm}$ for $1 / 3$ resorption, and $0.10 \mathrm{~mm}$ for $1 / 3-1 / 2$ resorption [32].

The values of displacement resulting from the application of force maintain a significant linear increase in our study, coupled with the increase in the magnitude of the applied force, with no significant differences for no periodontal disease and 33\% bone loss. However, in the $66 \%$ bone loss, the values of $\mathrm{f}$ are significantly greater, both compared to the intact periodontium and to the $33 \%$ group, depending on the magnitude of the applied force. One study that analyzed the biomechanical properties of desmodontium to assess intrusion through orthodontic force of $0.5,1$, and $3 \mathrm{~N}$ found that the location and the applied force levels were statistically significant in their effects on the modulus; the apical part also had greater stiffness. In this study, however, the authors proposed a heterogenous periodontium in which the modulus varied in relation to location [33].

The maximum equivalent tension in the tooth-periodontal ligament-alveolar bone complex ( $\sigma$ ech) is most affected by the magnitude of the applied force; close behind is tension in the direction of the force $(\sigma \mathrm{c})$, but the displacement values (f) were not affected significantly by the magnitude of the applied force.

Another significant aspect that must be taken into account is orthodontic appliance placement [34]. Research has pointed out that increasing the length of the brackets' hook can reduce the stress on the periodontal ligament. Thus, a $7 \mathrm{~mm}$-long hook delivered $22 \mathrm{kPa}$, while a bracket without a hook, $80 \mathrm{kPa}$. Moreover, by the apical angulation of the applied force from $0^{\circ}$ to $30^{\circ}$ there was a diminution on the effect of the periodontium stress profile [35]. A more streamlined tooth movement can be obtained, with less stress along on the desmodontium, by simply increasing the length of the bracket hook due to the application of the force closer to the center of resistance.

In the lower incisor model, the maximum equivalent tensions and tensions in the direction of the applied force show linear growth when the periodontium is healthy or affected $33 \%$; however, if the periodontium is affected $66 \%$, the increase shows an exponential progression, with significant higher values than those encountered in cases in which the periodontium was unaffected or affected to a lesser degree. Multivariate analysis yielded the predictive factors in the changes of the $\sigma$ ech and $\sigma \mathrm{c}$ values in the tooth-periodontal ligament-alveolar bone complex. The magnitude of the applied force and the extent to which the periodontium is affected have major impact in the case of lower incisors. However, in the case of displacement as a result of applying a lingualization force, correlation analysis showed that only the extent of periodontal damage significantly influences displacement, but the applied force does not. We also showed that none of the analyzed parameters was significantly influenced by the magnitude of the applied force, values of the tension recorded in the direction of force application, values of equivalent tension at the level of the tooth-periodontal ligament-alveolar bone complex, or values of the recorded displacement. 
A similar study to ours in design that analyzed a lower premolar model assessed the compressive stress quantitatively and qualitatively in periodontium for a model of gradual periodontal breakdown $(0-8 \mathrm{~mm})$ under orthodontic movements. The authors carried out correlations between bone resorption level, type of applied forces (intrusion, extrusion, rotation, tipping, and translation), and decrease of force magnitude. They found that the highest apical and cervical stress was caused by translation and rotation, whereas intrusion determined the lowest cervical stress to be higher than apical stress. For in-intact periodontium, only intrusion and extrusion exhibited compressive stresses lower than maximum hydrostatic pressure (MHP) and maximum tolerable stress (MTS). In reduced periodontium, however, compressive stress (except for intrusion) exceeded these two parameters; thus, in the case of periodontal breakdown, lighter forces of $0.2 \mathrm{~N}$ are considered safer, and anything exceeding 0.6-1.2 $\mathrm{N}$ may compromise the desmodontium by producing stresses surpassing both maximum tolerable stress and hydrostatic pressure. The authors did not observe a correlation between the applied force, compressive stress increase, and periodontal breakdown, applicable to all five movements [36]. These results are confirmed by our studies as we could not find a correlation between these parameters.

Lingualization in the lower frontal group is more important once the loss of attachment increases, both in terms of tensions in the system and in terms of the displacement per se, and, from a clinical point of view, in terms of unwanted side-effects. One of the possible deleterious effects is orthodontically induced inflammatory root resorption. When analyzing linear to nonlinear models, a study that considered pure intrusion, buccal tipping, and their combination, applied with either a light $(0.25 \mathrm{~N})$ or a heavy $(2.25 \mathrm{~N})$ force, found notable differences in stress distribution patterns and magnitude. None of the light-force models reached the critical compressive hydrostatic stress when a nonlinear periodontal ligament was considered, whereas all the heavy-force models reached it. Moreover, the authors observed that the areas of critical compressive hydrostatic stress corresponded to those with resorption craters in clinical studies [37].

Another potentially hazardous effect may occur, especially in the case of the LLI, because of the inherent root morphological characteristics and differences. Due to the anatomical features and location in the mandibular bone, the LLI is less protected when compared to the LCI. Our study emphasizes an increased risk of deleterious side-effects when applying a lingualization force to the LLI, with a potential emergence of the "wedge effect". This effect entails applying a higher amount of force on a significantly reduced surface, and it may be extremely damaging for the supporting periodontal tissues. When taking into account an affected periodontium, the periodontal prognosis may be extremely different between the two lower incisors; thus, clinicians should be aware of these important differences and apply a lighter force on the LLI.

The point of force application is also important. For example, the results obtained by Lombardo et al. showed that when the vertical force was applied on the lingual surface, a larger displacement was observed, and the type of the movement obtained was tipping. In addition, the authors stated that applying an intrusive lingual force to the lower incisor determines bodily movement and the same intrusive labial force determines labial tipping [38]. These observations also agree with another study that compared labial orthodontics to lingual orthodontics in terms of force magnitude. The differences in biomechanics of tipping were evaluated for a $50 \mathrm{~g}$ force applied on the labial and the lingual side, and the main stress patterns in the periodontal ligament for orthodontic tooth movement were recorded. The same force on the labial side caused approximately $0.0252 \mathrm{~N} / \mathrm{mm}^{2}$ maximum principal stress and on the lingual side it resulted in $0.0375 \mathrm{~N} / \mathrm{mm}^{2}$ maximum principal stress; thus, tipping for a lingually applied force requires about $1 / 3$ less force when compared to a labial one [34].

This study has several limitations. First, in order to simplify the analysis, we assumed that the tooth-periodontium-alveolar bone complex has linear elasticity and isotropic properties of the same quality; however, this is only an approximation of reality. Second, we only discussed the effect of a lingualization force on the lower incisors; however, 
other teeth might behave differently when submitted to orthodontic forces, especially multirooted teeth. We did, however, focus on these teeth due to the reduced bone thickness at this level in a majority of cases and the increased likelihood of further periodontal tissue breakdown during orthodontic treatment.

\section{Conclusions}

The lingualization of the lower anterior teeth is an essential stage during the interdisciplinary therapeutic approach of the adult periodontal patient. Our results showed that none of the analyzed parameters were significantly influenced by the magnitude of the applied force: $\sigma$ ech, $\sigma$ c, or $\mathrm{f}$. Thus, lingualization can be considered as a reliable option during complex periodontal treatment. Anatomical particularities should also be considered since they may contribute to increase in periodontal risk in case of lingualization of the LLI compared to that of the LCI, with a potential emergence of the "wedge effect". Thus, differences in anatomical features of the roots are important because they may influence the absorption of force by the supporting periodontium. Although orthodontic forces applied on anterior teeth with affected periodontium are very difficult to quantify in a clinical setting, we recommend that they should be light, efficient, and not exceed $1 \mathrm{~N}$, in order to minimize periodontal hazards.

Future studies are necessary, in order to investigate and validate our results; therefore, we consider that a correct and uniform protocol of orthodontic management in periodontal cases may significantly contribute to an increased rate of success with minimal associated risks.

Author Contributions: Conceptualization, I.L. and M.-A.M.; methodology, M.T., M.M.S., D.C.K.-N., and L.P.; software, I.-A.S.; writing—original draft preparation, M.-A.M. and I.L.; writing—review and editing, N.I.; supervision, S.M.S. and M.T. All authors have read and agreed to the published version of the manuscript.

Funding: This research received no external funding.

Institutional Review Board Statement: Not applicable.

Informed Consent Statement: Not applicable.

Data Availability Statement: All data are available from the corresponding authors upon reasonable request.

Acknowledgments: Mihaela Monica Scutaru and Nicoleta Ioanid have an equal contribution as the first author.

Conflicts of Interest: The authors declare no conflict of interest.

\section{References}

1. Antoun, J.S.; Mei, L.; Gibbs, K.; Farella, M. Effect of orthodontic treatment on the periodontal tissues. Periodontology 2000 2017, 74, 140-157. [CrossRef] [PubMed]

2. Sioustis, I.-A.; Martu, M.-A.; Aminov, L.; Pavel, M.; Cianga, P.; Kappenberg-Nitescu, D.C.; Luchian, I.; Solomon, S.M.; Martu, S. Salivary Metalloproteinase-8 and Metalloproteinase-9 Evaluation in Patients Undergoing Fixed Orthodontic Treatment before and after Periodontal Therapy. Int. J. Environ. Res. Public Health 2021, 18, 1583. [CrossRef] [PubMed]

3. Pai, S.S.; Panda, S.; Pai, V.; Anandu, M.; Vishwanath, E.; Suhas, A.S. Effects of labial and lingual retraction and intrusion force on maxillary central incisor with varying collum angles: A three-dimensional finite elemental analysis. J. Indian Orthod. Soc. 2017, 51, 28-37. [CrossRef]

4. Luchian, I.; Moscalu, M.; Martu, I.; Vata, I.; Stirbu, C.; Olteanu, D.; Pasarin, L.; Martu, M.A.; Solomon, S.; Anton, D.; et al. Perspectives and limits of mandibular lateral incisor intrusion associated with periodontal disease. A FEM study. Rom. J. Oral Rehabil. 2018, 10, 60-70.

5. Kumar, A.; Konda, P. Patterns of Stress Distribution During Simple Tooth Movements: A Finite Element Study. Indian J. Stomatol. 2012, 3, 226.

6. Srirekha, A.; Bashetty, K. Infinite to finite: An overview of finite element analysis. Indian J. Dent. Res. 2010, 21, 425. [CrossRef]

7. Huang, H.-L.; Tsai, M.-T.; Yang, S.-G.; Su, K.-C.; Shen, Y.-W.; Hsu, J.-T. Mandible Integrity and Material Properties of the Periodontal Ligament during Orthodontic Tooth Movement: A Finite-Element Study. Appl. Sci. 2020, 10, 2980. [CrossRef] 
8. Jones, M.L.; Hickman, J.; Middleton, J.; Knox, J.; Volp, C. A validated finite element method study of orthodontic tooth movement in the human subject. J. Orthod. 2014, 16. [CrossRef] [PubMed]

9. Tatarciuc, M.; Maftei, G.A.; Vitalariu, A.; Luchian, I.; Martu, I.; Diaconu-Popa, D. Inlay-Retained Dental Bridges-A Finite Element Analysis. Appl. Sci. 2021, 11, 3770. [CrossRef]

10. Luchian, I.; Vata, I.; Martu, I.; Stirbu, C.; Tatarciuc, M.; Martu, S. The periodontal effects of an optimal intrusive force on a maxillary central incisor. A FEM evaluation. Rom. J. Oral Rehabil. 2016, 8, 51-55.

11. Kanjanaouthai, A.; Mahatumarat, K.; Techalertpaisarn, P.; Versluis, A. Effect of the inclination of a maxillary central incisor on periodontal stress: Finite element analysis. Angle Orthod. 2012, 82, 812-819. [CrossRef] [PubMed]

12. Hemanth, M.; Deoli, S.; Raghuveer, H.P.; Rani, M.S.; Hegde, C.; Vedavathi, B. Stress induced in periodontal ligament under orthodontic loading (Part II): A comparison of linear versus non-linear FEM study. J. Int. Oral Health 2015, 7, 114.

13. Jain, A.; Prasantha, G.S.; Mathew, S.; Sabrish, S. Analysis of stress in periodontium associated with orthodontic tooth movement: A three dimensional finite element analysis. Comput. Methods Biomech. Biomed. Eng. 2021, 1, 1. [CrossRef] [PubMed]

14. Seo, J.H.; Eghan-Acquah, E.; Kim, M.S.; Lee, J.H.; Jeong, Y.H.; Jung, T.G.; Hong, M.; Kim, W.H.; Kim, B.; Lee, S.J. Comparative Analysis of Stress in the Periodontal Ligament and Center of Rotation in the Tooth after Orthodontic Treatment Depending on Clear Aligner Thickness-Finite Element Analysis Study. Materials 2021, 14, 324. [CrossRef]

15. Fill, T.S.; Toogood, R.W.; Major, P.W.; Carey, J.P. Analytically determined mechanical properties of, and models for the periodontal ligament: Critical review of literature. J. Biomech. 2012, 45, 9-16. [CrossRef]

16. Bhalajhi, S.I. Dental Anatomy-Histology and Development; Arya Publishing House: New Dehli, India, 2009; pp. 51-139.

17. Hohmann, A.; Kober, C.; Young, P.; Dorow, C.; Geiger, M.; Boryor, A.; Sander, F.M.; Sander, C.; Sander, F.G. Influence of different modeling strategies for the periodontal ligament on finite element simulation results. Am. J. Orthod. 2011, 139, 775-783. [CrossRef]

18. Caballero, G.M.; Carvalho Filho, O.A.; Hargreaves, B.O.; Brito, H.H.; Magalhães Júnior, P.A.; Oliveira, D.D. Mandibular canine intrusion with the segmented arch technique: A finite element method study. Am. J. Orthod. Dentofac. Orthop. 2015, 147, 691-697. [CrossRef] [PubMed]

19. Kurgan, S.; Terzioglu, H.; Yilmaz, B. Stress distribution in reduced periodontal supporting tissues surrounding splinted teeth. Int. J. Periodontics Restor. Dent. 2014, 34, 93-101. [CrossRef] [PubMed]

20. Xia, Z.; Jiang, F.; Chen, J. Estimation of periodontal ligament's equivalent mechanical parameters for finite element modeling. Am. J. Orthod. Dentofac. Orthop. 2013, 143, 486-491. [CrossRef]

21. Theodorou, C.I.; Kuijpers-Jagtman, A.M.; Bronkhorst, E.M.; Wagener, F.A. Optimal force magnitude for bodily orthodontic tooth movement with fixed appliances: A systematic review. Am. J. Orthod. Dentofac. Orthop. 2019, 156, 582-592. [CrossRef]

22. Flores-Mir, C. Forces Between 50 and $100 \mathrm{cN}$ May be Best for Mesiodistal Orthodontic Tooth Movements by Fixed Appliances. J. Evid. Based Dent. Pract. 2020, 20, 101490. [CrossRef] [PubMed]

23. Romanyk, D.L.; Vafaeian, B.; Addison, O.; Adeeb, S. The use of finite element analysis in dentistry and orthodontics: Critical points for model development and interpreting results. Semin. Orthod. 2020, 26, 162-173. [CrossRef]

24. Cuoghi, O.A.; Topolski, F.; de Faria, L.P.; Ervolino, E.; Micheletti, K.R.; Miranda-Zamalloa, Y.M.; Moresca, R.; Moro, A.; de Mendonça, M.R. Correlation between pain and hyalinization during tooth movement induced by different types of force. Angle Orthod. 2019, 89, 788-796. [CrossRef] [PubMed]

25. Rudolph, D.J.; Willes, M.G.; Sameshima, G.T. A finite element model of apical force distribution from orthodontic tooth movement. Angle Orthod. 2001, 71, 127-131.

26. Gupta, M.; Madhok, K.; Kulshrestha, R.; Chain, S.; Kaur, H.; Yadav, A. Determination of stress distribution on periodontal ligament and alveolar bone by various tooth movements-A 3D FEM study. J. Oral Biol. Craniofac. Res. 2020, 10, 758-763. [CrossRef]

27. Vikram, N.R.; Kumar, K.S.; Nagachandran, K.S.; Hashir, Y.M. Apical stress distribution on maxillary central incisor during various orthodontic tooth movements by varying cemental and two different periodontal ligament thicknesses: A FEM study. Indian J. Dent. Res. 2012, 23, 213. [CrossRef] [PubMed]

28. Li, Z.; Yu, M.; Jin, S.; Wang, Y.; Luo, R.; Huo, B.; Liu, D.; He, D.; Zhou, Y.; Liu, Y. Stress distribution and collagen remodeling of periodontal ligament during orthodontic tooth movement. Front. Pharmacol. 2019, 10, 1263. [CrossRef]

29. Cattaneo, P.M.; Dalstra, M.; Melsen, B. Strains in periodontal ligament and alveolar bone associated with orthodontic tooth movement analyzed by finite element. Orthod. Craniofac. Res. 2009, 12, 120-128. [CrossRef]

30. Zargham, A.; Geramy, A.; Rouhi, G. Evaluation of long-term orthodontic tooth movement considering bone remodeling process and in the presence of alveolar bone loss using finite element method. Orthod. Waves 2016, 75, 85-96. [CrossRef]

31. Toms, S.R.; Eberhardt, A.W. A nonlinear finite element analysis of the periodontal ligament under orthodontic tooth loading. Am. J. Orthod. Dentofac. Orthop. 2003, 123, 657-665. [CrossRef]

32. Ma, Y.; Li, S. The optimal orthodontic displacement of clear aligner for mild, moderate and severe periodontal conditions: An in vitro study in a periodontally compromised individual using the finite element model. BMC Oral Health 2021, 21, 109. [CrossRef]

33. Uhlir, R.; Mayo, V.; Lin, P.H.; Chen, S.; Lee, Y.T.; Hershey, G.; Lin, F.C.; Ko, C.C. Biomechanical characterization of the periodontal ligament: Orthodontic tooth movement. Angle Orthod. 2017, 87, 183-192. [CrossRef] [PubMed]

34. Mascarenhas, R.; Chatra, L.; Shenoy, S.; Husain, A.; Mathew, J.M.; Parveen, S. A comparative study of forces in labial and lingual orthodontics using finite element method. J. Indian Orthod. Soc. 2015, 49, 15-18. [CrossRef] 
35. Ammar, H.H.; Ngan, P.; Crout, R.J.; Mucino, V.H.; Mukdadi, O.M. Three-dimensional modeling and finite element analysis in treatment planning for orthodontic tooth movement. Am. J. Orthod Dentofac. Orthop. 2011, 139, e59-e71. [CrossRef]

36. Moga, R.A.; Buru, S.M.; Chiorean, C.G.; Cosgarea, R. Compressive stress in periodontal ligament under orthodontic movements during periodontal breakdown. Am. J. Orthod. Dentofac. Orthop. 2021, 159, e291-e299. [CrossRef] [PubMed]

37. Roscoe, M.G.; Cattaneo, P.M.; Dalstra, M.; Ugarte, O.M.; Meira, J.B. Orthodontically induced root resorption: A critical analysis of finite element studies' input and output. Am. J. Orthod. Dentofac. Orthop. 2021, 159, 779-789. [CrossRef] [PubMed]

38. Lombardo, L.; Stefanoni, F.; Mollica, F.; Laura, A.; Scuzzo, G.; Siciliani, G. Three-dimensional finite-element analysis of a central lower incisor under labial and lingual loads. Prog. Orthod. 2012, 13, 154-163. [CrossRef] 